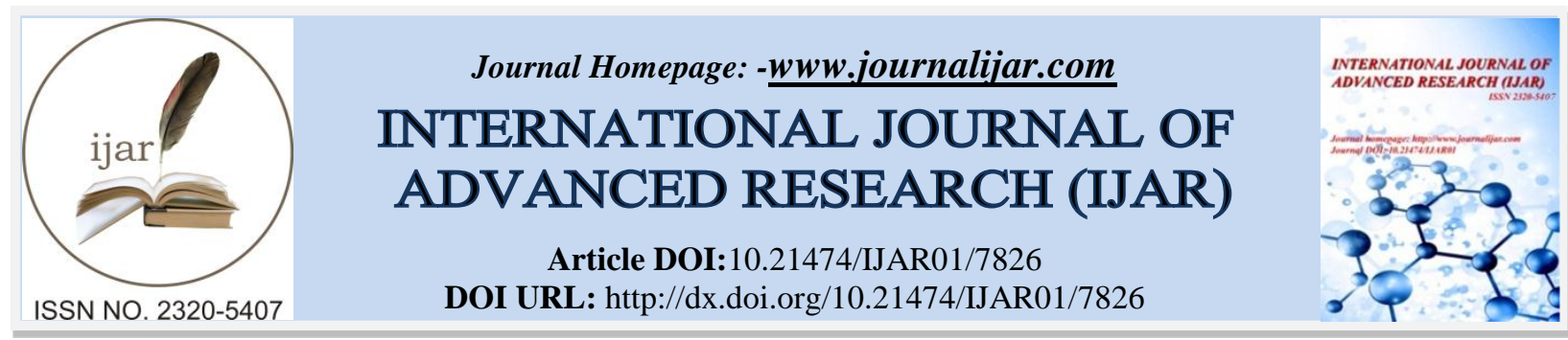

RESEARCH ARTICLE

\title{
CONTRIBUTION OF RADAR INSPECTIONS TO THE IDENTIFICATION OF THE STATE OF CIVIL ENGINEERING WORKS.
}

\author{
Yvette Tankpinou Kiki ${ }^{1,2}$, Ernesto C. Houehanou ${ }^{1,2}$, Marx F. Ahlinhan ${ }^{1}$, Issiakou M. Souley ${ }^{3}$ and \\ Emmanuel K. Wouya1 ${ }^{1}$. \\ 1. National University of Sciences, Technologies, Engineering and Mathematics, (UNSTIM), Abomey, Benin. \\ 2. Laboratory of Materials and Structures (LAMS), Abomey-Calavi University, Cotonou, Benin. \\ 3. Laboratory of Soil Analysis and Public Works Monitoring (Niger).
}

\section{Manuscript Info}

-.......................

Manuscript History

Received: 7 August 2018

Final Accepted: 9 September 2018

Published: October 2018

Keywords:-

Key words: Inspection, evaluation, radar, non-destructive measurements, structures, civil engineering.

\section{Abstract}

Civil engineering works age and degrade over time. In the context of sustainable development and from both economic and environmental perspectives, it is often more advantageous to rehabilitate existing structures than building new ones. There comes the necessity of expertise in order to gain a thorough knowledge of their state of deterioration, the extent and causes of such deterioration, their residual lifetime, etc. In this line, the radar, a non-destructive testing method, emerges as the most appropriate research instrument in that it does not affect the structure of the works examined. However, this instrument is uncommonly used. That is why the present paper aims at contributing its popularization through the assessment of the state of some civil engineering works based on specific data derived from non-destructive measurements made with the radar.

Copy Right, IJAR, 2018,. All rights reserved.

\section{Introduction:-}

Despite significant progress in the knowledge of the behavior of building materials and their design methods, the problem of deterioration of structures remains. Degradations of reinforced concrete are varied and reach the cement matrix, aggregates and/or reinforcements. Their origins are very numerous: formulation or implementation defects, aggressive environment, positioning of reinforcements, chemical transformations and variable alterations of the aggregates according to their origin [Ezzdine, 2009].

Regardless of such structural problems, five major mechanisms of degradation are commonly distinguished [Ezzdine, 2009]: carbonation (a natural phenomenon of concrete aging that mainly results in reinforcement corrosion); attack of chlorides starting from $0.65 \%$ of cement weight [standard NF P18-011] ; Sulfatic attack that initially produces secondary ettringite leading to a swelling of the concrete and its cracking; alkali reaction: that manifests itself after several decades in the form of cracking or bursting of the concrete; thermal expansion causing expansion and contractions that are variable depending on the minerals that make up the rock.

In addition, with the aging building heritage, the issues at stake are huge. That is why it is therefore urgent to find innovative and effective monitoring and instrumentation methods to address these problems. 
The use of a diagnosis makes it possible to establish the inventory of pathologies linked to building structure in order to confirm or invalidate the satisfactory state of the structure [A.F.G.C. 2005, Clemena 1983]. In this line, geophysical methods provide responses to the aging of structures so as to improve their safety and extend their life. Many techniques are available to characterize pathologies on structures. They are chosen according to the objectives of the study. These techniques are most often combined with each other to provide a fairly comprehensive diagnosis. The Radar-based diagnosis technique intervenes in order to repair the disorders of a deteriorated structure most often still in use [Dérobert 2003, May 2015]. In the case of civil engineering, the radar technique is mainly used to determine the position of steels in concrete [Dérobert and Coffec 2001], their state of corrosion [Laurens et al. 2001, Sbartaï et al., 2005], the location of underground cavities, the characterization of masonry, etc. The measurements thus obtained can be interpreted in the form of coating statistics, cartography or reinforcement principle in the case of a reinforced concrete structural element. The presentation of the results of this auscultation technique experimented on four practical cases is the subject of this article.

\section{Materials And Methods:- \\ Principle of method}

Radar-based diagnosis technique is based on the propagation of electromagnetic pulses of very short duration, emitted by a transmitter and an antenna specifically adapted for a non-air environment (Fig. 01). These pulses are partly reflected towards the surface by an interface between two materials that have different electromagnetic characteristics (relative dielectric permittivity $\varepsilon r$ ). The unreflected part continues its way to the next interface, where a second echo occurs, and so successively on each interface. Successive echoes are received by a receiving antenna generally located near the transmitting antenna. The receiver therefore measures the amplitude of the electric field as a function of time. This measurement, for a fixed position of the antennas, corresponds to a "scan" [Garciaz, 2009]. Objects of spherical or cylindrical shape are represented on the radargram by diffraction hyperbolas.

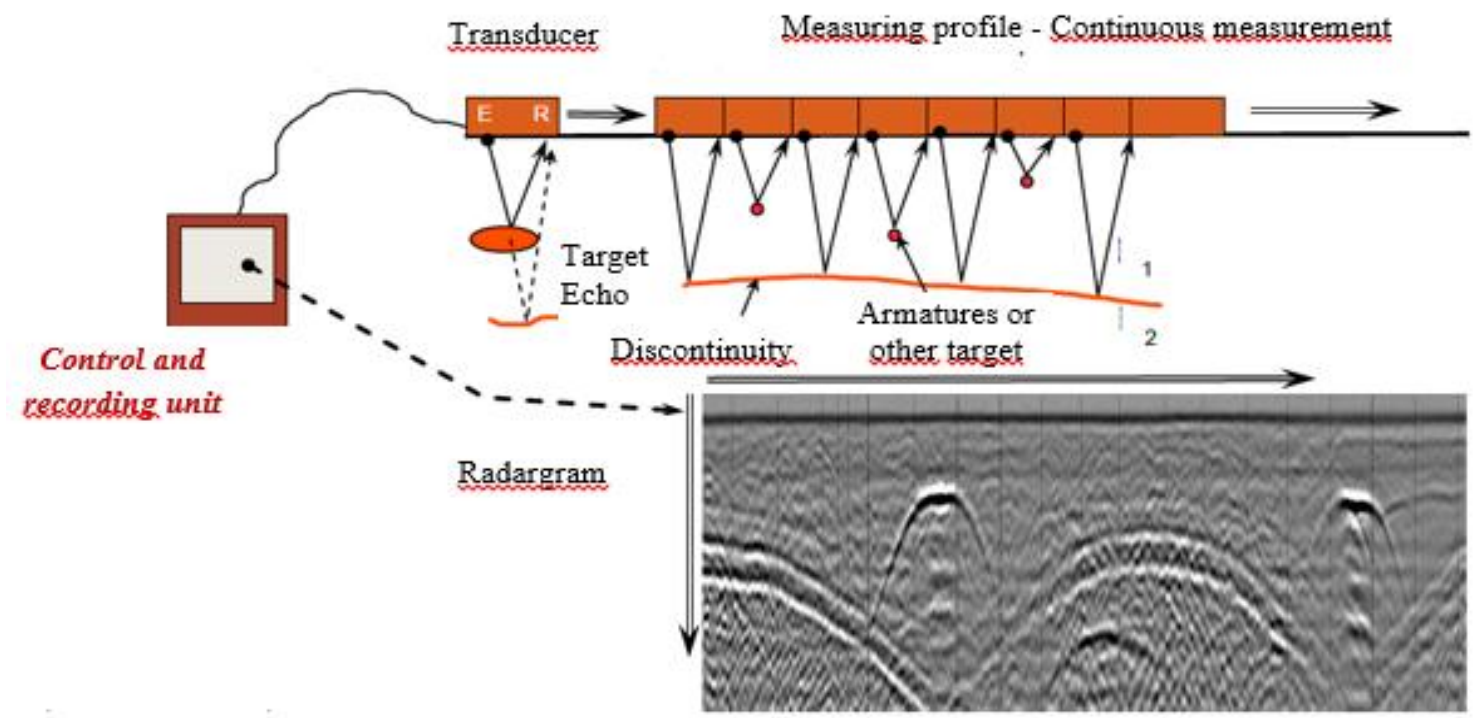

Figure 01:-Principle of radar investigation and radargram recording

\section{Radar Equipment}

The acquisition equipment that has been used consists of a radar, a computer for recording real-time measurements and an encoder connected to the antenna. The "encoder - antenna" system is connected to the radar via a connector. Several antennas of varying frequencies were used: higher frequencies for shallower investigations, and lower frequencies for deeper investigations (Fig. 02). 


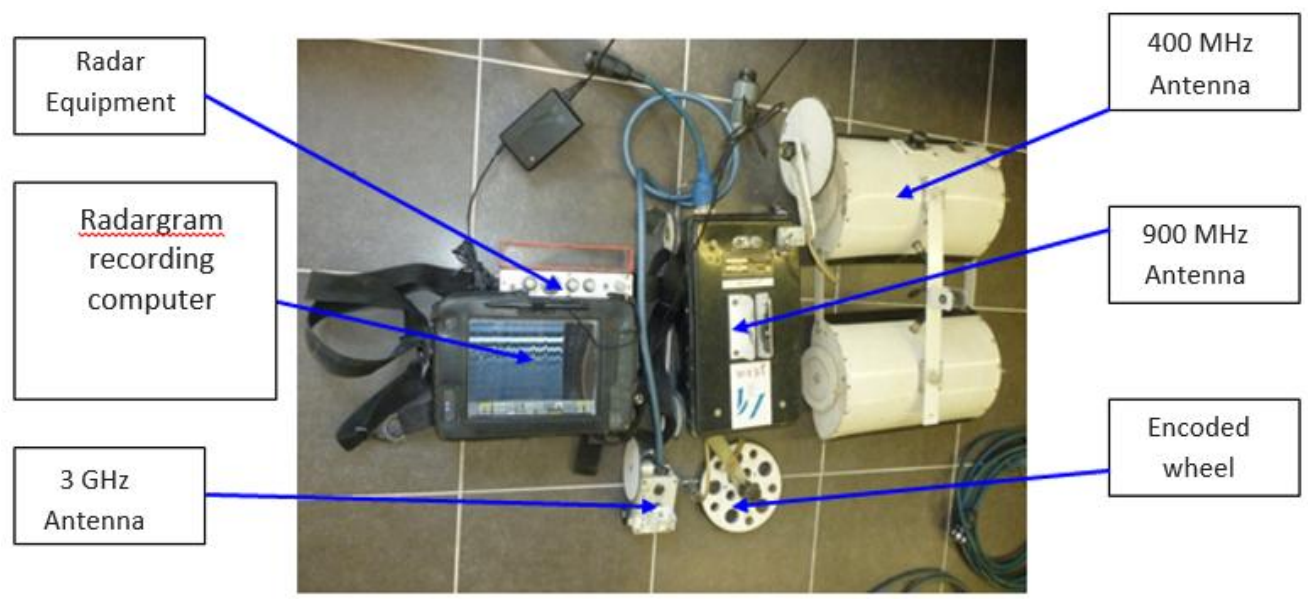

Figure 02 :-Equipement radar et différentes antennes

\section{On-site methodology}

Radar-based investigations begin with the selection of appropriate areas. This choice is made wisely according to the observed disorders and the objectives of the study. To ensure the reliability of the measures, parallel profiles and crossed profiles were combined at $90^{\circ}$. Once the area that is close to the opening has been selected, the meshing was carried out by choosing a constant measure between the profiles in both directions as done for the mapping of coating.

1. The quality of acquisition depends on the choice of the parameters based on targets. The main decisive parameters in auscultation are:

2. The dielectric constant $(\varepsilon)$ : to assess the real depths of targets;

3. Number of scans per meter: a number of scans between 100 and 150 scans/meter is chosen for the auscultation of reinforced concrete according to the size of the meshes.

4. The listening time: its choice depends on the selected antenna.

5. Vertical sampling: the default is chosen equal to 512 scans/meter, but during the examination of collected data, 256 scans/meter are often sufficient for analysis.

The processing of radargrams was done using the software called VISURAD-XP.

\section{Results And Discussions:-}

\section{Coating statistic of a reinforced concrete building}

Investigations are conducted on a building where all the structural elements are prefabricated. The aim of the study is to establish a coating statistic to control the coating of steels of structural elements (sails, lintels, amounts, arches, etc.).

After auscultation, several radargrams are recorded. The coating of an armature laid bare accidentally is only $3 \mathrm{~mm}$, while the minimum coating required for such a structure (structural class $\mathrm{S} 4$ and exposure class XC2 and XC3) is at least $25 \mathrm{~mm}$ [Eurocode 2].

An example of a radargram, recorded on the support of a building bay is shown in Figure 3 (the irons are indicated in red). 


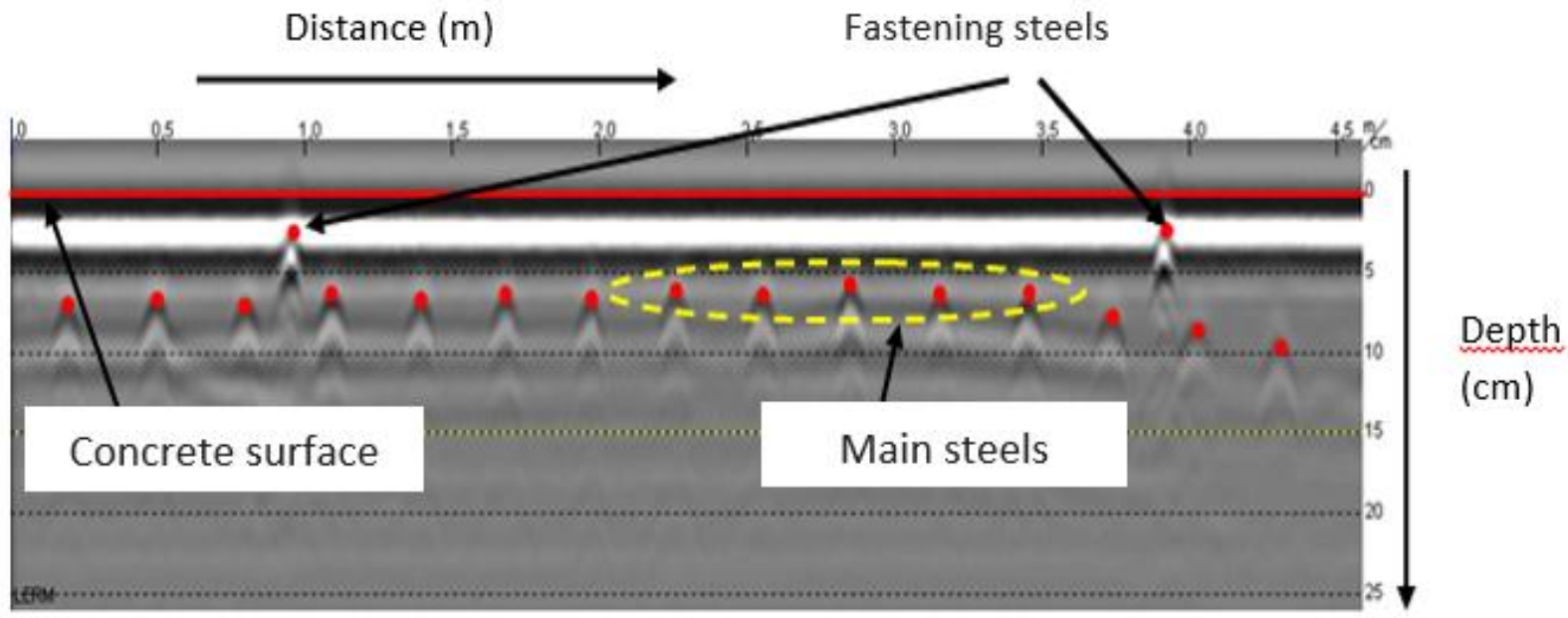

Figure 02:-Radargram corresponding to the support of the bay

A statistic distribution diagram of the coatings is made for each type of surface examined (soffit, bay supports, bay amount ...). A distinction has also been made between vertical steels and horizontal steels (Table 01). Finally, on each diagram is recorded the minimum coating measured.

Table 01:-Synthetic results on the amount of bay

\begin{tabular}{|c|c|c|}
\hline Armatures & Minimum coating $(\mathrm{mm})$ & $\begin{array}{c}\text { \% of irons having a coating }<25 \\
\mathrm{~mm}\end{array}$ \\
\hline Vertical (external) & 20 & 30 \\
\hline Horizontal (external) & 19 & 31 \\
\hline Vertical (internal) & 29 & 0 \\
\hline Horizontal (internal) & 25 & 2 \\
\hline Support & 10 & 12 \\
\hline Underside of the lintel & 20 & 56 \\
\hline Montants & $<10$ & 30 \\
\hline
\end{tabular}

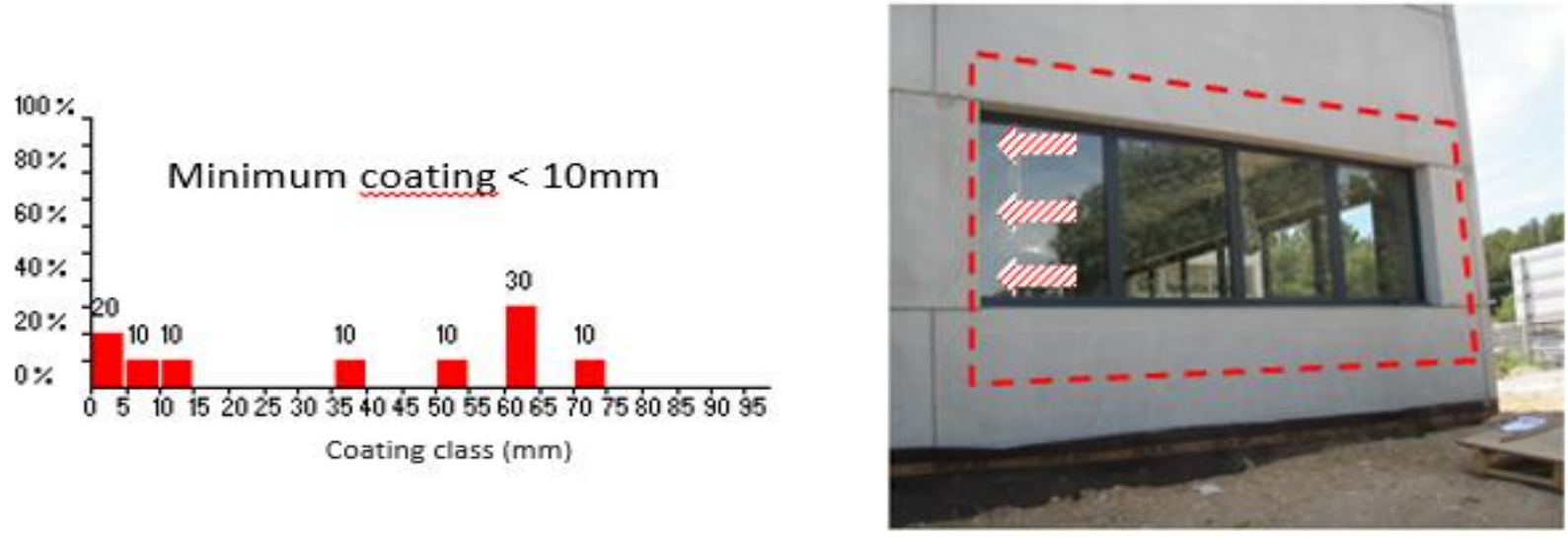

Figure 03:-Statistical distribution of reinforcement coatings in depth increments

On the diagrams of the bay, only the vertical and horizontal (interior) reinforcing bars have a coating greater than or equal to the required value. Therefore, these parts of the work have a coating sufficient to protect steels against aggressive agents. The other parts are strongly undercoated or slightly undercoated and the amount indicated by hatching in the photo (Fig. 04) has a coating less than $10 \mathrm{~mm}$.

In order to obtain an overall view of the coating of steels, the diagram (Fig. 05) shows the statistical distribution of the coatings calculated on the entire building. It appears in total that: 
1. $2 \%$ of the steels, whose coating is less than $15 \mathrm{~mm}$, are strongly undercoated,

2. $19 \%$ of the steels, whose coating is between 15 and $25 \mathrm{~mm}$, present a risk of corrosion with regard to the theoretical coatings required.

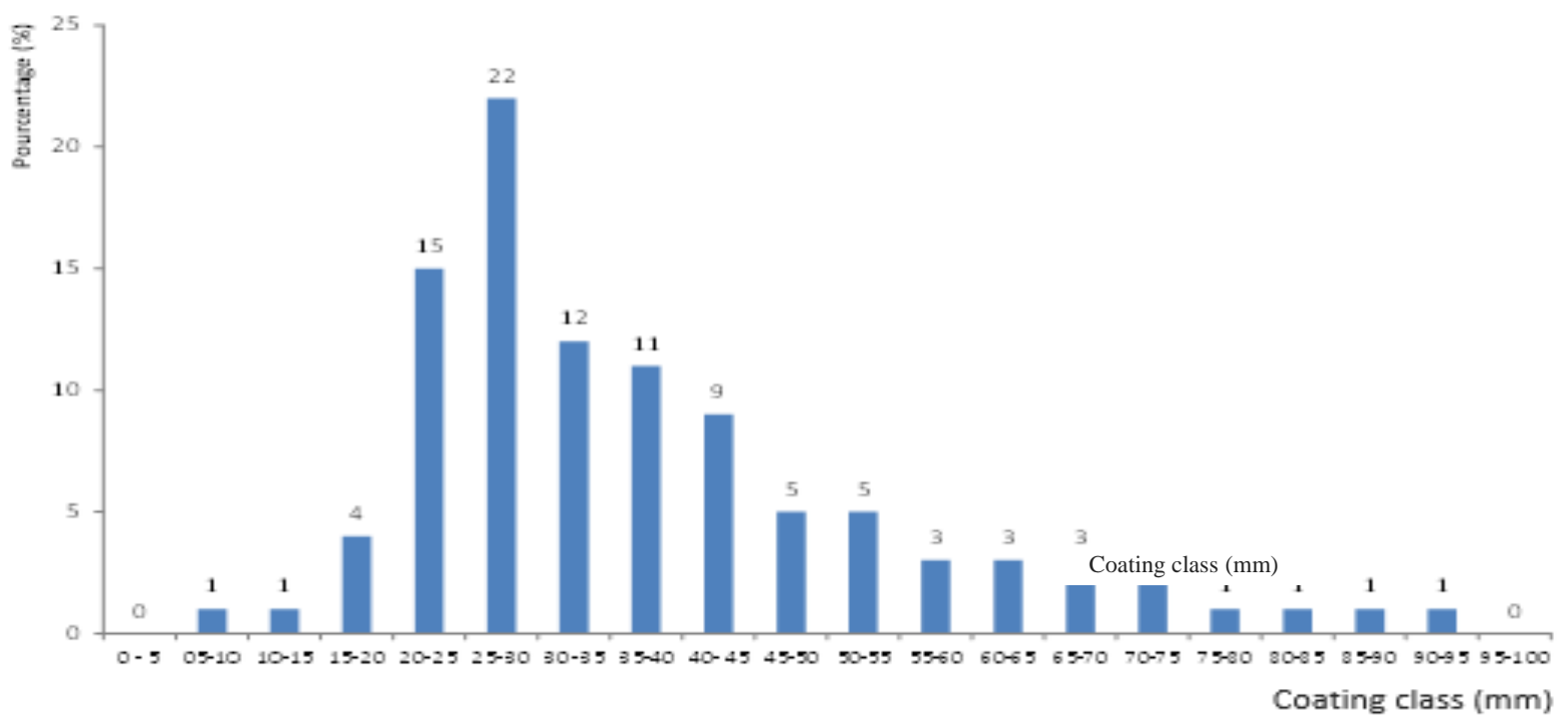

Figure 04:-General diagram of coating statistics

\section{Coating mapping for a water tank}

The coating map is a map made on a well-defined surface. It highlights the two-dimensional arrangement of steels in concrete while clarifying their depths by a palette of colors. The most coated reinforcement is in blue while the less coated are in red.

This study is carried out on a water tank. After defining an area of $2 \mathrm{~m}^{2}$, vertical and horizontal profiles were made with the radar. A horizontal sampling of 150 scans / meter is chosen together with a listening time of 5 nanoseconds and a dielectric constant of 9.5 after calibration. The concrete is wet. After data processing, a reinforcement mapping is performed and coupled to a coating statistic. The distribution of rebars in concrete is shown in Figure 6.

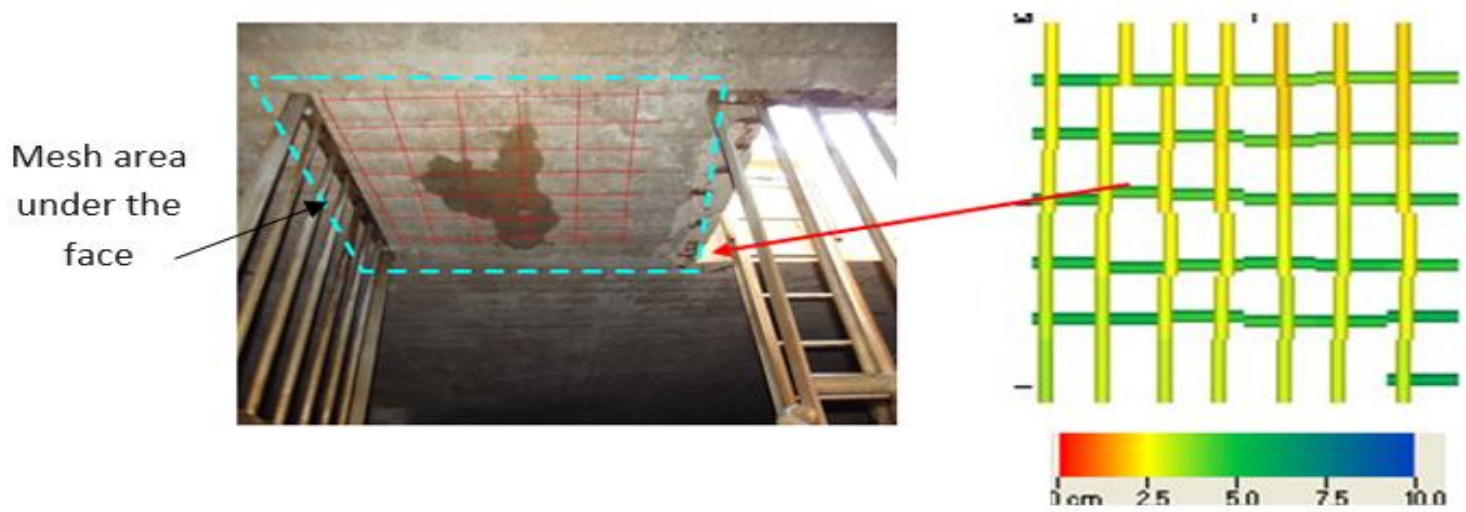

Figure 05:-Coatingmapping

Referring to the color palette, the mapping highlights that vertical frames are slightly under coated. Their coating oscillates between 25 and $50 \mathrm{~mm}$, while the horizontal frames are well coated, between 50 and $75 \mathrm{~mm}$. This study was conducted in order to establish a diagnosis. As a result, the following key points to the level of the face of the slab of the tank cover have been identified: the minimum coating of steels is $15 \mathrm{~mm}(92 \%$ of the frames in the fringe (0-30 mm). 


\section{Reinforcement Principle for a Prestressed Beam Independent Viaduct (VIPP)}

The reinforcement principle is realized to investigate the distribution of the reinforcement of a structural element in reinforced concrete. This study concerns a VIPP and its purpose is to locate passive steels and prestressed steels so as to represent them on transverse and longitudinal views, while specifying their depths in the concrete and their spacing.

During the investigations, passive steels (in blue) and prestressing sheaths (in red) are identified. The spacer is bordered by two beams, the waiting steels (in green) connecting them are also detected. A difficult detection zone, given the density of irons and the thickness of concrete, is located in the center of the spacer.A representation in the form of a cross section (Fig. 07) and a longitudinal section (Fig. 08) are given.

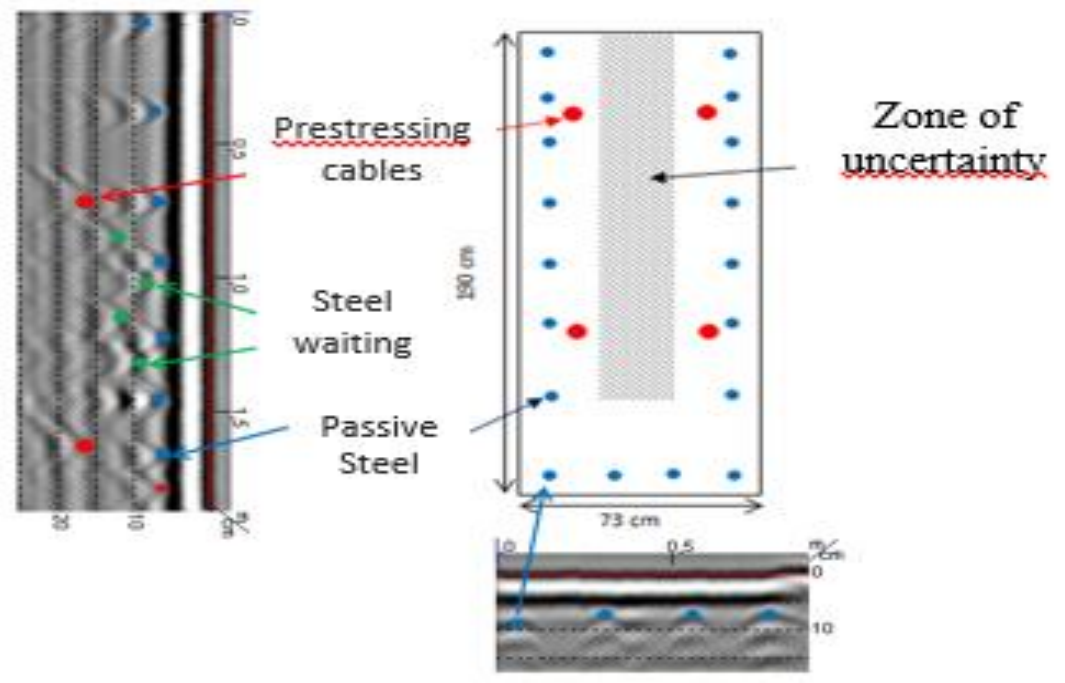

Figure 06:-Transverse view showing steels position

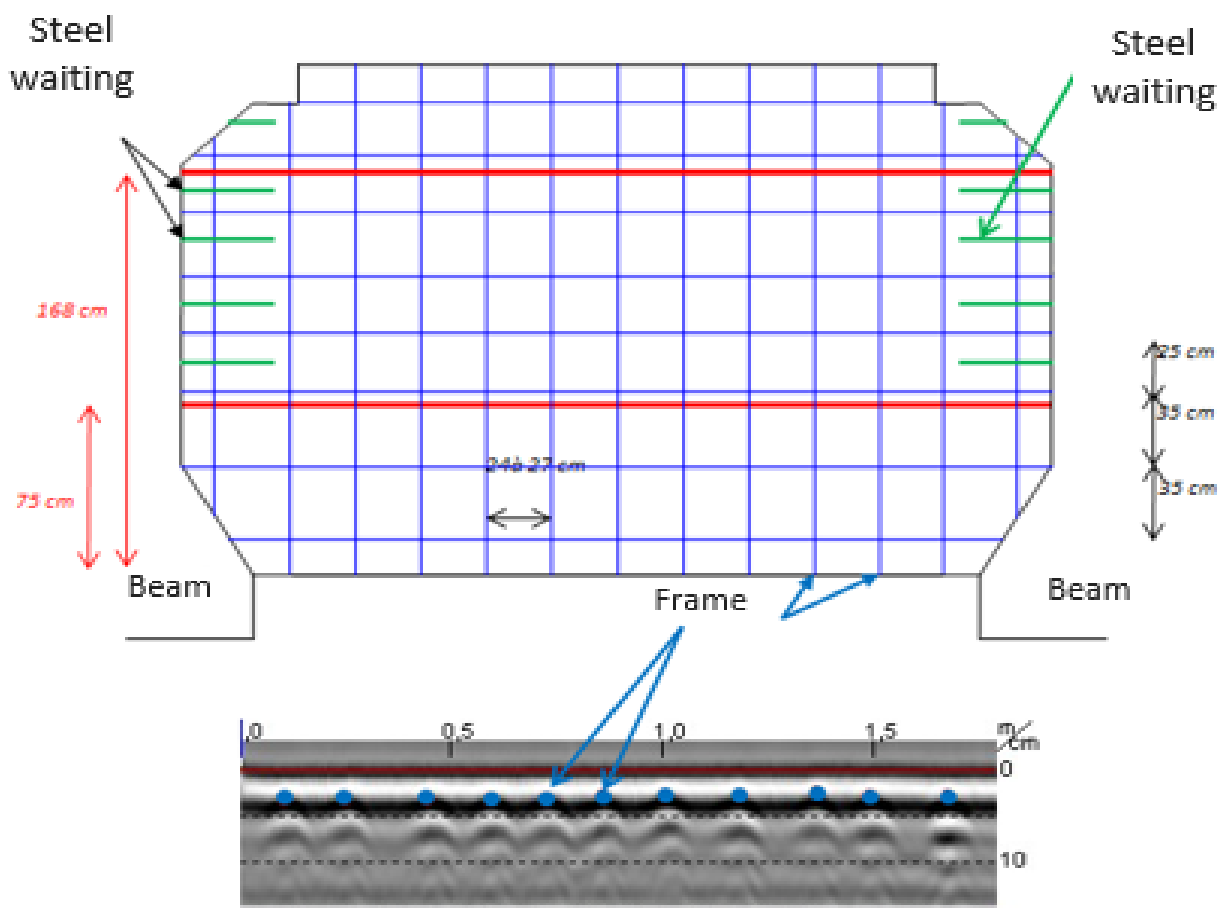

Figure 07:-Longitudinal view showing steels position 


\section{Masonry: Inventory of pathologies}

As part of the restoration work of an old castle, a diagnosis is made by highlighting the condition of the facade walls and remission of some chimneys in the tall towers of a building.

Two modes of representation are chosen for the purpose of this study: the radar section to represent anomalies and the thickness of the wall in depth along a plane parallel to the facing wall on the one hand and the cartography to represent information on the plane obtained by analyzing together several radar sections on a wall of significant size on the other hand. The interpretation of the localized anomalies in the different zones (wall of roof, vault and facade of the tower) is presented as follows:

\section{Shear wall}

The wall has a hole where the thickness is the thinnest (anomaly on the left). The zone of anomalies corresponds to a decompressed masonry work or containing small voids distributed in a heterogeneous way. The rest of the wall is homogeneous, a sign of good internal cohesion of the masonry.

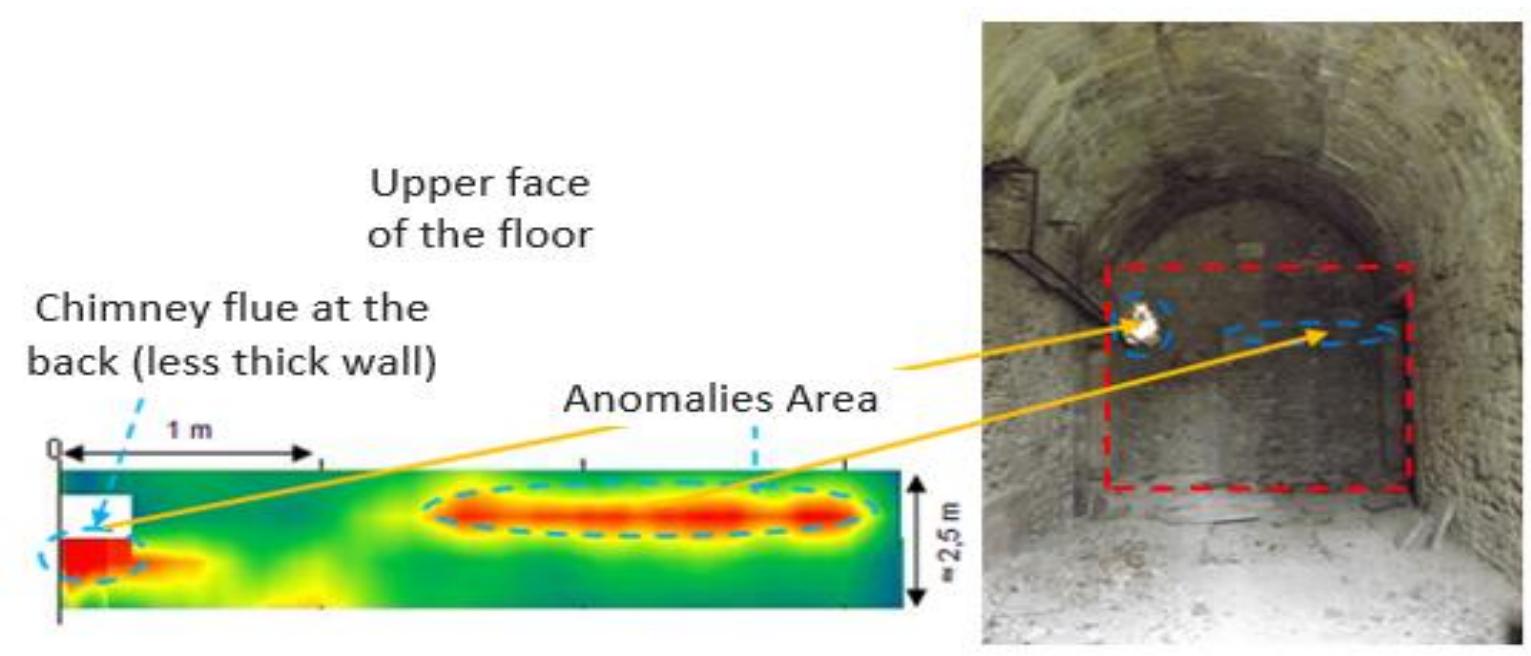

Figure 9:-Cartography and photography

\section{Vault}

The vault has been studied from the underside. It appears that the total keystone thickness reaches $110 \mathrm{~cm}( \pm 20 \%)$. The interface observed at the brick/internal fill limit indicates a minimum thickness of the brick face of about $50 \mathrm{~cm}$. (Figure 10)

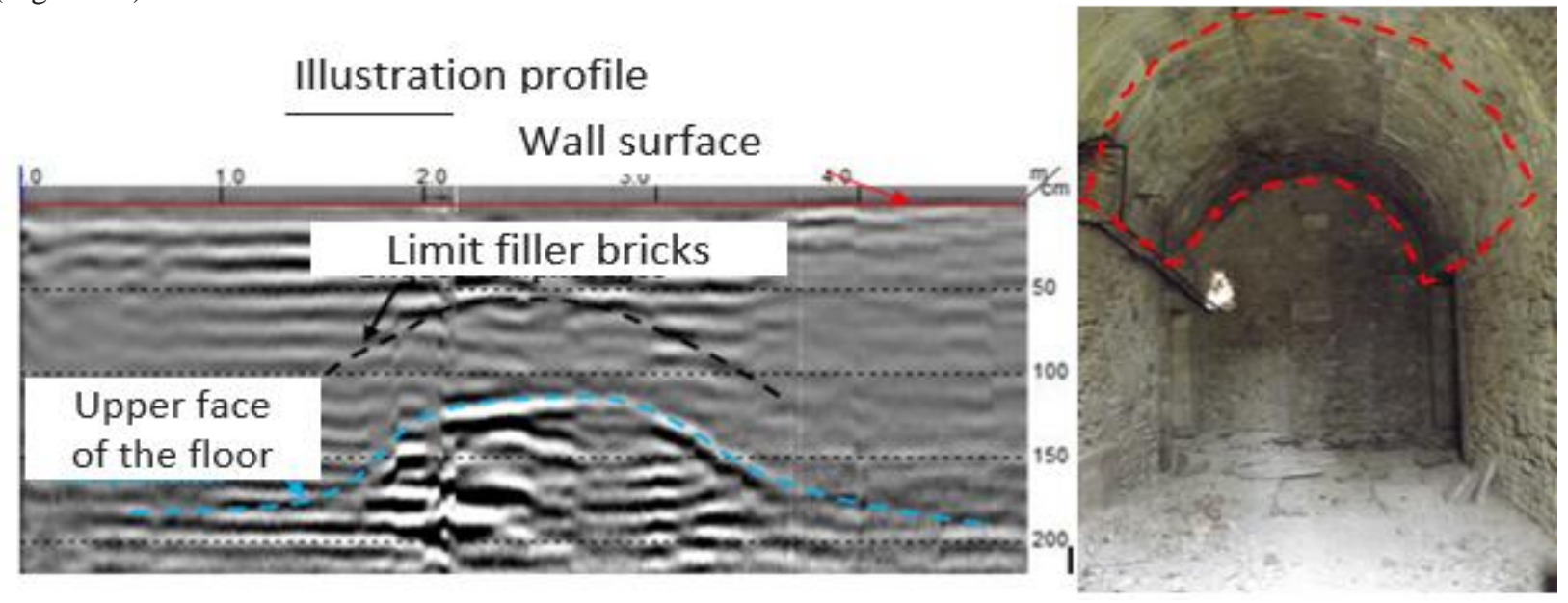

Figure 8:-Illustration profile and photography 


\section{Facade}

The mapping is carried out for a depth of investigation intersecting the internal duct of the chimney. Its trajectory is dashed. Some generalized anomalies (in yellow) on the lower map reflect a certain degree of heterogeneity of the masonry (presence of small voids and constitution in little cohesive mortar mortars). These results are correlated with the coring carried out at the bottom of the tower which has revealed a very friable nature of the mortar in the middle of the wall. The facade also shows signs of internal fractures visible from the outside, with the presence of decimetric roots, which walk in the middle of the bricks (Figure 11). In addition, the strong red anomalies at the edges of the openings are due to the presence of the stones paired: they do not reflect a defect in masonry.

Overall, it emerges from the radar study that the thickest walls are less homogeneous than others.

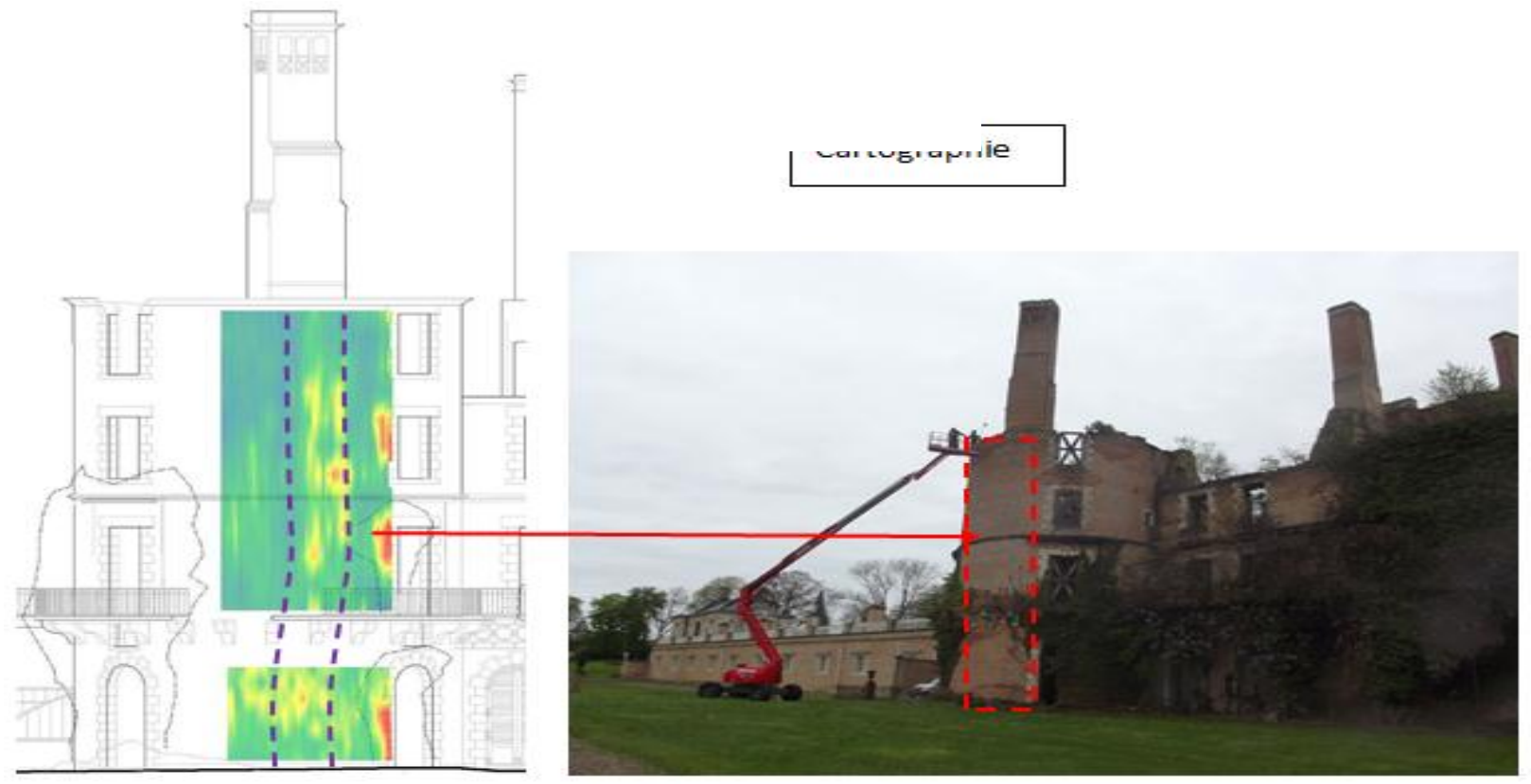

Figure 11:-Cartography and photography of the tower

\section{Conclusion:-}

Several possibilities for the interpretation of investigations by non-destructive measurements with the radar on civil engineering works exist and make it possible to have precise information which can lead to the evaluation of the state of works in course of aging.

During the study, the coating state of the steels and the distribution of reinforcements were highlighted in different types by a coating statistic and a coating map. On masonry works, it was easy to make an inventory of pathologies. These results make it possible to have the first elements of answer that can guide future decisions. 


\section{Bibliography:-}

1. A.F.G.C. (2005). Méthode d'évaluation non destructive de l'état d'altération des ouvrages en béton. Presses de l'école nationale des Ponts et Chaussées pp 235 - 301.

2. Clemena G. C. (1983). "Non-destructive Inspection of Overlaid Bridge Decks with Ground Penetrating radar.'Transportation Research Record (No. 899): pp. 21-32.

3. Dérobert X., Coffec O. (2001), "Localisation des armatures des ouvrages d'art enbétonarméouprécontraint par les techniques de radar", Bulletin des Laboratoires des PontsetChaussées, vol. 230, janvier-février 2001, pp 5765

4. Dérobert X. (2003), "Techniques radar appliquées au génie civil", LCPC, nJ1050343, ISSN 1167- 4865

5. EzzdineRana (2009). Endommagement des monuments historiquesenmaçonnerie. Thèse de l'Université de Bordeaux 1

6. Garciaz (2009). Contribution des auscultations radar à la reconnaissance des maçonneriesd'ouvrages. LERM

7. Laurens, S., Balayssac, J.-P., Rhazi, J., Arliguie, G. (2001), Le radar : une nouvelle application pour l'évaluationnon-destructive de la corrosion des armatures du béton, Congrès de la ConfédérationFrançaise des Essais non Destructifs (COFREND) sur le "contrôle non destructif de la corrosion", Reims (France)

8. Mai T. C. (2015). Evaluation non-destructive des matériaux de construction par technique électromagnétique aux fréquences radar - modélisationetexpérimentationenlaboratoire. Thèse de l'Université de Bordeaux.

9. Sbartaï, Z.M., Laurens, S., Rhazi, J., Balayssac, J.P., G. Arliguie, G. (2005). Non Destructive Assessment of Corrosion Risks By Using Radar And Electrical Resistivity Measurements: Laboratory Experimentation and On-Site Investigation, Proc. Int. Cong. on Construction Rehabilitation and Sustainable Development, Algérie, $10 \mathrm{p}$. 